\title{
Openness, Economic Development, and the Environment in Post-Reform China: A Model with Empirical Analysis
}

\author{
Yanqing Jiang \\ School of Economics and Finance, Shanghai International Studies University, Shanghai, P. R. China \\ Correspondence: Yanqing Jiang, School of Economics and Finance, Shanghai International Studies University, No. \\ 1550 Wenxiang Rd., Shanghai 201620, P. R. China
}

Received: May 2, 2014

Accepted: May 19, $2014 \quad$ Available online: June 2, 2014

doi:10.11114/ijsss.v2i3.403

URL: http://dx.doi.org/10.11114/ijsss.v2i3.403

\begin{abstract}
In this study, based on the Environmental Kuznets Curve (EKC) framework, we empirically examine the effects of trade openness and the level of economic development on pollution emission across the Chinese provinces. Our regression analysis shows that increasing trade openness contributes to higher pollution emission, where the effect of the former may be realized through its impacts on total factor productivity and the industry mix. Our analysis also shows that with the continuous growth of output and per capita output, pollution emission and pollution emission intensity both first rise and then fall, which gives support to the EKC hypothesis.
\end{abstract}

Keywords: openness, environment, pollution emission, development, China

\section{Introduction}

Thanks to the market-oriented reforms initiated in the late 1970s, China has achieved spectacular growth in the past several decades, and its economic structure has experienced great transformation. In the meantime, the whole country has also gradually opened up to foreign trade and foreign direct investment, transforming itself from a virtually completely closed economy into a major trading nation and the largest developing-country destination for foreign direct investment in the world. The ratio of foreign trade to GDP quadrupled from 9 percent in 1980 to 36 percent in 2000, over a period of twenty years.

However, it is argued that the rapid processes of industrial development and opening up have been relying heavily on increasing inputs of environmental resources. Unsustainable environmental practices are posing serious threats to China's forests, water, air, biodiversity, and energy and food supplies (Co, Kong and Lin, 2008). In 2007, for example, China replaced the United States and became the largest greenhouse gas emitter in the world. Direct damages from environmental pollution have stayed as high as 8 to 10 percent of total annual GDP of China (The Economist, 2004). Environmental pollution accompanying China's rapid economic growth, opening up and development has become a serious concern that calls for the rethinking of government policies (Zhang, 2012).

The linkages between foreign trade, economic development and the environment have been widely discussed in the literature. They have been mostly investigated within the framework of the Environmental Kuznets Curve (EKC hereinafter), which postulates an inverted U-shaped relationship between environmental pollution and per capita income (Grossman and Krueger, 1993, 1995). In the EKC framework, increased incomes are associated with an increase in pollution in poor economies but a decline in pollution in rich economies.

Foreign trade may affect pollution outcomes through a variety of channels. One channel is the scale effect considered harmful to the environment, which describes the situation where the expansion of domestic production driven by increasing trade openness leads to more environmental pollution. Another channel is the technique effect considered conducive to the environment: domestic firms could enjoy the spillovers introduced by foreign trade and have access to more advanced technologies that are less pollutive. Through this channel, trade openness could improve the environmental quality. A third channel is the composition effect, which is related to structural changes that occur in the economy: foreign trade shapes the pattern of production specialization between the country and the rest of the world, and therefore, by driving the reallocation of resources across different domestic sectors, affects the overall pollution intensity of the various production activities within the country. Still one more channel is the income channel: along with the income gains allowed by foreign trade, the country may desire higher environmental standards, more stringent 
regulations, and better enforcement by the government, which are all beneficial to the environment.

Early studies within the EKC framework focused on the effect of economic development on environmental degradation (Grossman and Krueger, 1993, 1995; Selden and Song, 1994; Vincent, 1997; Gale and Mendez, 1998). However, the relationship between income growth and the environment may vary with the source of income growth, as different types of economic activities have different pollution intensities (Abdulai and Ramcke, 2013). In other words, the pollution consequences of economic growth depend on the underlying sources of growth (Antweiler, Copeland and Taylor, 2001). Further, the simplest EKC framework does not account for the effects of foreign trade on the environment. In fact, trade patterns may partially explain reductions in pollution in high-income countries and meanwhile increases in pollution in low-income countries. Specifically, the pollution haven hypothesis postulates that disparities in the stringency of environmental regulations between developed and developing countries will generally lead to increased pollution-intensive production in the developing countries (Cole, 2004). The factor endowment hypothesis, in comparison, argues that determined by trade and specialization patterns, countries that are relatively abundant in factors used intensively in polluting industries will generate more pollution as trade barriers are lifted (Mani and Wheeler, 1998).

We are interested in uncovering the environmental implications of China's processes of opening up and economic development. In this paper, therefore, we empirically examine the effects of trade openness and the level of development on pollution emission across the Chinese provinces. Environmental resources are unpaid factors of production in an unregulated market, as the cost of pollution is not internalized. Pollution emission thus can be viewed as an additional factor of production (besides labor, capital, etc.) into the aggregate production function (Tzouvelekas, Vouvaki and Xepapadeas, 2006). To examine the effects of foreign trade and economic development on pollution emission in China is effectively to see whether China is contributing a substantial amount of environmental resources to the production of its total economic output. Under a green Solow growth framework (see, for example, Brock and Taylor, 2004), environmentally sustainable development in China requires that while technological progress in goods production is necessary to generate per capita income growth in the Chinese regions, technological progress in these regions in terms of emission reduction must exceed growth in output in order for pollution to fall and the environment to improve (Jiang, 2013).

This paper is organized as follows. In Section 2, we present our basic model. In Section 3, we discuss issues related to the sample, data and variables. In Section 4, we present and discuss our regression results. Section 5 extends our analysis to incorporate the possibility of strategic interaction among provinces into our regression model. Finally, Section 6 concludes.

\section{The Basic Model}

To consider the theoretical model, we assume that aggregate output of a given single-sector economy at time $t$ is linked its various production factors by an aggregate production function of the form

$$
Y(t)=F[K(t), L(t), N(t), A(t)]
$$

where $K$ is the level of physical capital stock, $L$ is the amount of human labor, $N$ is the quantity of natural resources used in the production process, and $A$ stands for the level of technology or total factor productivity. The simple idea behind our theoretical model is that the production process itself generates pollution emission, which means that the amount of pollution emitted is not directly related to the level of aggregate output, but to the quantities of the various production factors (including total factor productivity) employed in the production process. Therefore, the amount of pollution emitted can be treated as a function of the various arguments in (1). Formally, for this given economy, we can write

$$
E(t)=\rho[K(t), L(t), N(t), A(t)]
$$

where $E(t)$ stands for pollution emitted at time $t$. Since the level of total factor productivity $A(t)$ is not directly observable, we can write it as

$$
A(t)=\varphi[Y(t), K(t), L(t), N(t)]
$$

which is implicitly determined by the functional relationship in (1). Plugging (3) into (2) yields

$$
\begin{gathered}
E(t)=\rho\{K(t), L(t), N(t), \varphi[Y(t), K(t), L(t), N(t)]\} \\
=\tilde{E}[Y(t), K(t), L(t), N(t)]
\end{gathered}
$$

where the second equality redefines the function. Equation (4) shows that pollution emission $E(t)$ can be written as a function of four arguments, which are output $Y(t)$, physical capital $K(t)$, labor $L(t)$ and natural resources $N(t)$.

It is now straightforward to consider the situation of an economy with $m$ different sectors. Pollution emission of the $j$ th sector $(j=1,2, \ldots, m)$ is determined by 


$$
E^{j}(t)=\widetilde{E}^{j}\left[\varphi_{Y}^{j}(t) Y(t), \varphi_{K}^{j}(t) K(t), \varphi_{L}^{j}(t) L(t), \varphi_{N}^{j}(t) N(t)\right]
$$

where the $\varphi$ 's are respectively the shares of economy-wide $Y(t), K(t), L(t)$ and $N(t)$ in sector $j$, with the sum of all the $\varphi$ 's equaling one for any $t$ Total pollution emission of the whole economy at time $t$ is now written as

$$
E(t)=\sum^{m} \widetilde{E}^{j}\left[\varphi_{Y}^{j}(t) Y(t), \varphi_{K}^{j}(t) K(t), \varphi_{L}^{j}(t) L(t), \varphi_{N}^{j}(t) N(t)\right]
$$

Therefore, the total economy-wide poif

$$
E(t)=\tilde{\widetilde{E}}[Y(t), K(t), L(t), N(t), \boldsymbol{\Phi}(t)]
$$

in which $\boldsymbol{\Phi}(t)$ is a vector containing all the $\varphi$ 's.

The empirical model used in our analysis is directly based on Equation (7), with openness to foreign trade incorporated into the regression specification as an additional explanatory variable. Our baseline econometric model, which takes account of the EKC framework and applies a panel data structure, is then expressed as follows

$$
\begin{gathered}
\ln E_{i t}=\beta_{1} \ln T_{i t}+\beta_{2} \ln Y_{i t}+\beta_{3}\left(\ln Y_{i t}\right)^{2}+\beta_{4} \ln L_{i t}+\beta_{5}\left(\ln L_{i t}\right)^{2} \\
+\beta_{6} \ln K_{i t}+\beta_{7}\left(\ln K_{i t}\right)^{2}+\delta_{t}+c_{i}+\varepsilon_{i t}
\end{gathered}
$$

in which all the variables are entered in the logarithm form. The explained variable $E_{i t}$ is regional pollution emission (of province $i$ in year $t$ ). The explanatory variables are regional trade openness $T_{i t}$, regional output (i.e. GDP) $Y_{i t}$, regional population $L_{i t}$, and regional physical capital stock $K_{i t}$. The squared terms of the latter three are also included in the equation to take account of potential nonlinear partial effects as predicted by the EKC framework. The terms $\delta_{t}$, $c_{i}$ and $\varepsilon_{i t}$ are the time-variant intercept, the time-constant province heterogeneity, and the zero-mean idiosyncratic error, respectively.

The variable $T_{i t}$, which represents regional trade openness, is our primary explanatory variable. According to the specification in (8), the coefficient $\beta_{1}$ on $\ln T_{i t}$, which bears an elasticity interpretation of $\beta_{1}=\partial \ln E_{i t} / \partial \ln T_{i t}$, indicates the magnitude (in the percentage sense) of the partial effect of $T_{i t}$ on pollution emission $E_{i t}$, netting out the effects of regional output, regional population and regional physical capital stock. It should be noted that according to Equation (7) above, when $Y, K$ and $L$ are controlled for, regional trade openness can only affect regional pollution emission $E$ through its impacts on $\boldsymbol{\Phi}$ and $N$. To fix ideas, suppose (fictitiously) for the moment that all the elements in $\Phi$ are held fixed, then with $Y, K$ and $L$ being controlled for, trade openness can only affect the level of $E$ by affecting the level of $N$ employed in the production process. According to Equation (3), this is equivalent to saying that with $Y, K, L$ as well as all the elements in $\boldsymbol{\Phi}$ held fixed, trade openness can only affect the level of pollution emission $E$ by affecting the level of total factor productivity $A$. Now suppose, instead, that the level of $N$ (besides the levels of $Y, K$ and $L$ ) is held fixed, then according to Equation (7), we see that trade openness can now affect the level of $E$ only by affecting the shares in $\boldsymbol{\Phi}$. In sum, our regression specification in (8) captures two different channels through which regional openness to foreign trade may exert impacts on regional pollution emission. First, trade openness may affect pollution emission by affecting total factor productivity. Second, trade openness may affect pollution emission by affecting the industry mix.

The magnitude of the partial effect of $\ln Y_{i t}$ on $\ln E_{i t}$ is determined by $\beta_{2}+2 \beta_{3} \ln Y_{i t}$, where a non-zero value of $\beta_{3}$ indicates a nonlinear partial effect of $\ln Y_{i t}$ on $\ln E_{i t}$. Since in Equation (8) the variables $L_{i t}$ and $K_{i t}$ are both controlled for, we can see that an increase in regional output $Y_{i t}$ would affect the level of regional pollution emission $E_{i t}$ through channels other than increases in labor and capital inputs. For example, an increase in $Y_{i t}$ given the levels of $L_{i t}$ and $K_{i t}$ may imply an increase in the level of total factor productivity $A_{i t}$, which in turn would affect the quantity of pollution emitted. Or otherwise an increase in $Y_{i t}$ (given the levels of $L_{i t}$ and $K_{i t}$ ) may imply an increase in the input of natural resources (see Equation (1)), which may also reasonably affect the level of pollution emission $E_{i t}$. The magnitude of the partial effect of $\ln L_{i t}$ on $\ln E_{i t}$ is determined by $\beta_{4}+2 \beta_{5} \ln L_{i t}$. A non-zero value of $\beta_{5}$ implies a nonlinear partial effect of $\ln L_{i t}$ on $\ln E_{i t}$. As both $Y_{i t}$ and $K_{i t}$ are controlled for in the regression equation, a change in $L_{i t}$ is then associated with a change in either $A_{i t}$ or $N_{i t}$ (or both). Similarly, the magnitude of the partial effect of $\ln K_{i t}$ on $\ln E_{i t}$ is determined by $\beta_{6}+2 \beta_{7} \ln K_{i t}$. A non-zero value of $\beta_{7}$ captures a nonlinear partial effect of $\ln K_{i t}$ on $\ln E_{i t}$. Because of the inclusion of the terms $\ln Y_{i t}$ and $\ln L_{i t}$ (and their squared terms as well) in the regression equation, a change in $K_{i t}$ is associated with a change in either $A_{i t}$ or $N_{i t}$ (or both).

\section{The Data}

Our sample includes 28 provincial-level regions (provinces for short) in China over the period of 1997-2010. ${ }^{1}$ We use the total volume of provincial industrial waste gas emission (in 100 million cubic meters) to proxy for total provincial

\footnotetext{
1 These provincial-level regions include provinces, ethnic minority autonomous regions, and provincial-level municipalities. Because of missing data, three regions, Tibet, Chongqing, and Hainan are not included in our sample.
} 
pollution emission $E_{i t}$ of a Chinese province (province $i$ ) in any given year (year $t$ ). Cross-sectional data on provincial industrial waste gas emission for each year in 1997-2010 are available from the Chinese Statistical Yearbook (the issues of 1997-2011) so that the panel of data on $E_{i t}$ can be obtained. Cross sections of provincial population for each year in 1997-2010 can also be found in the Yearbook (1997-2011) so that the panel of data on $L_{i t}$ can be directly obtained. Cross sections of nominal Gross Regional Product (GRP) and GRP indices for each year in 1997-2010 are also available from the Yearbook (1997-2011), so that the panel of data on real provincial GRP can be calculated for $Y_{i t}$.

However, the various issues of the Chinese Statistical Yearbook do not directly record data on provincial physical capital stock $K_{i t}$ for the Chinese provinces. Therefore, to calculate the levels of provincial physical capital stock, we opt for the procedure of Zhang (2008), who applies a perpetual inventory method (PIM) to calculate physical capital stock data for the Chinese provinces. The PIM procedure of Zhang (2008) leads to an annual rate of depreciation for fixed capital formation of 9.6\% across all the provinces over the period 1952-2004. In our current analysis, by following the same procedure, we therefore assume that the annual depreciation rates of physical capital are uniformly $9.6 \%$ for all the 28 provinces throughout our sample period $1997-2010 .^{2}$

The trade openness variable $T_{i t}$ is constructed as the ratio of provincial foreign trade (exports plus imports) to provincial GRP, where data on the values of provincial exports and imports are also available from the Chinese Statistical Yearbook (the issues of 1997-2011). In a broader sense, regional openness to foreign trade can be understood as a proxy for the general level of regional openness to overall international economic activities. In fact, it may be more interesting to investigate the effect of regional openness to overall international economic activities (rather than openness to foreign trade in the narrow sense) on regional pollution emission. However, using trade openness to proxy for openness to overall international economic activities may give rise to a problem. A large province (in terms of output or population) may tend to have relatively less foreign trade, as there is a larger scope for trade within the province. In addition, a rich province (one with a high level of per capita output) may be biased toward having a lower level of trade-to-output ratio, because as the province develops, the share of the service sector tends to increase while the service sector is largely non-tradable (Low, Olarreaga and Suarez, 1998).

One way to tackle this problem is to adjust the trade openness variable (i.e. the trade-to-output ratio) so as to take account of disparities in region size and the level of regional development. We can consider a regression such as the following one, in which we regress the regional trade-to-output ratio (in the $\log$ form) on a set of variables measuring the region size (in terms of both output and population) and the level of regional development

$$
\begin{gathered}
\ln T_{i t}=\theta_{0}+\gamma_{1} \ln Y_{i t}+\gamma_{2}\left(\ln Y_{i t}\right)^{2}+\gamma_{3} \ln L_{i t}+\gamma_{4}\left(\ln L_{i t}\right)^{2} \\
+\gamma_{5} \ln \left(Y_{i t} / L_{i t}\right)+\gamma_{6}\left[\ln \left(Y_{i t} / L_{i t}\right)\right]^{2}+v_{i t} \\
=\theta_{0}+\theta_{1} \ln Y_{i t}+\theta_{2}\left(\ln Y_{i t}\right)^{2}+\theta_{3} \ln L_{i t}+\theta_{4}\left(\ln L_{i t}\right)^{2}+\theta_{5}\left(\ln Y_{i t} \cdot \ln L_{i t}\right)+v_{i t}
\end{gathered}
$$

where $v_{i t}$ is the error term of this regression, and $\theta_{1} \equiv \gamma_{1}+\gamma_{5}, \theta_{2} \equiv \gamma_{2}+\gamma_{6}, \theta_{3} \equiv \gamma_{3}-\gamma_{5}, \theta_{4} \equiv \gamma_{4}+\gamma_{6}$ and $\theta_{5} \equiv-2 \gamma_{6}$. We run a pooled ordinary least squares (OLS) regression according to (9) and construct the corresponding fitted value, denoted $\hat{T}_{i t}$, such that

$$
\hat{T}_{i t}=\exp \left[\hat{\theta}_{0}+\hat{\theta}_{1} \ln Y_{i t}+\hat{\theta}_{2}\left(\ln Y_{i t}\right)^{2}+\hat{\theta}_{3} \ln L_{i t}+\hat{\theta}_{4}\left(\ln L_{i t}\right)^{2}+\hat{\theta}_{5}\left(\ln Y_{i t} \cdot \ln L_{i t}\right)\right]
$$

where the $\hat{\theta}$ 's are the values of the intercept and slopes in (9) estimated from our pooled OLS regression. The fitted value $\hat{T}_{i t}$, calculated according to (10), indicates what the "normal" or average degree of openness of a Chinese province would have, given the level of regional output and the size of regional population. Based on this idea, the adjusted regional openness variable can be constructed as

$$
\ddot{T}_{i t} \equiv T_{i t} / \hat{T}_{i t}
$$

Or equivalently

$$
\ln \ddot{T}_{i t} \equiv \ln T_{i t}-\ln \hat{T}_{i t}=\hat{v}_{i t}
$$

which shows that the adjusted regional openness variable $\ln \ddot{T}_{i t}$ (in the $\log$ form) is actually the residual $\hat{v}_{i t}$ obtained from our pooled OLS regression based on (9).

We should note that our baseline regression specification in (8) already has $\ln Y_{i t}, \ln L_{i t}$ and their squared terms $\left(\ln Y_{i t}\right)^{2}$ and $\left(\ln L_{i t}\right)^{2}$ as independent variables: the only independent variable that appears in (9) but not in (8) is the interaction term $\left(\ln Y_{i t} \cdot \ln L_{i t}\right)$. We can now expand Equation (8) to include this interaction term as an additional explanatory variable

\footnotetext{
${ }^{2}$ See Zhang (2008) for more details.
} 


$$
\begin{gathered}
\ln E_{i t}=\beta_{1} \ln T_{i t}+\beta_{2} \ln Y_{i t}+\beta_{3}\left(\ln Y_{i t}\right)^{2}+\beta_{4} \ln L_{i t}+\beta_{5}\left(\ln L_{i t}\right)^{2} \\
+\beta_{6} \ln K_{i t}+\beta_{7}\left(\ln K_{i t}\right)^{2}+\beta_{8}\left(\ln Y_{i t} \cdot \ln L_{i t}\right)+\delta_{t}+c_{i}+\varepsilon_{i t}
\end{gathered}
$$

One merit of this new specification in (13) is that it controls for everything that is controlled for in (9), so that technically, it makes no difference whether it is $\ln T_{i t}$ or $\ln \ddot{T}_{i t}$ that really appears on the right-hand side of Equation (13). In our analysis below, for comparison purposes, we run regressions based on both (8) and (13).

Before we turn to our regression analysis, we informally examine the relationships between regional pollution emission (per unit of output) and several other variables in order to gain an intuitive idea of the descriptive statistics of our sample. First, we depict the relationship between regional pollution emission intensity (i.e. pollution emission per unit of output) and regional trade openness in Figure 1, using pooled data of all the provinces over the whole sample period of 1997-2010 (392 observations altogether). The figure suggests a negative relationship between the two: the more open the province is to foreign trade, the lower the level of its pollution emission per unit of output (without controlling for other factors).

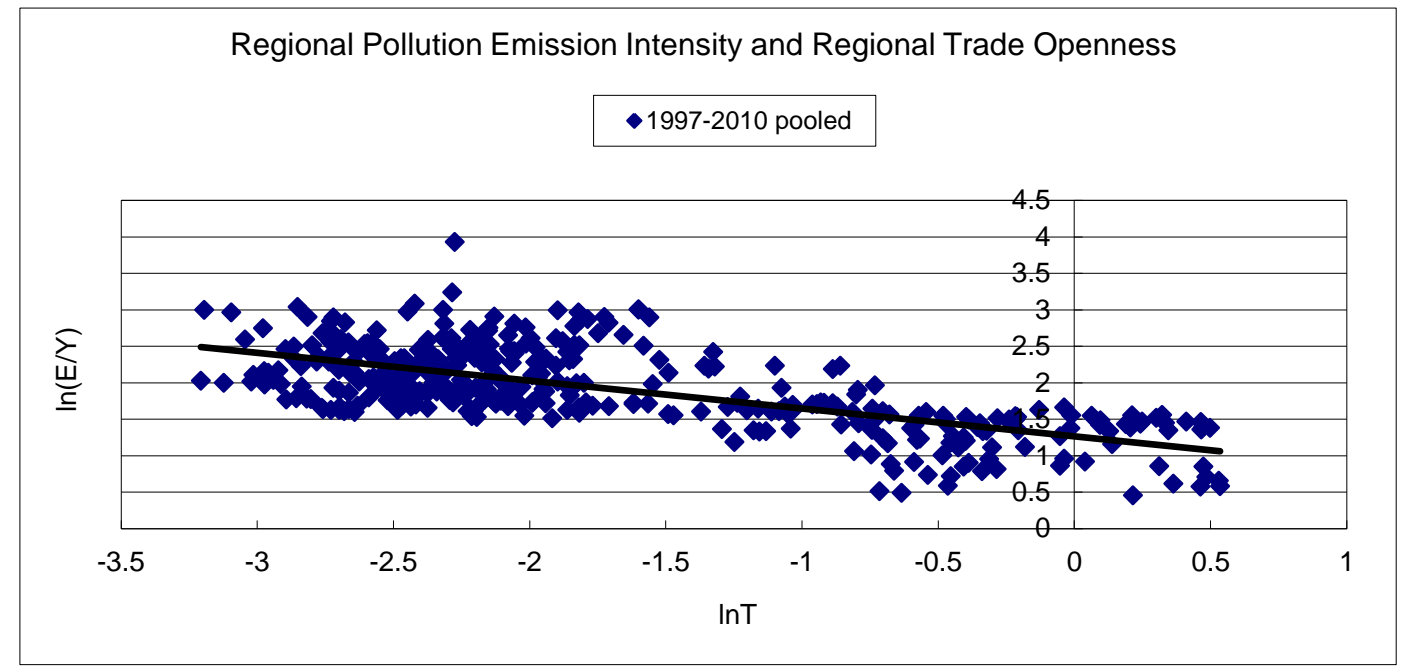

Figure 1. Regional Pollution Emission Intensity and Regional Trade Openness

Regional pollution emission intensity $\ln (E / Y)$ is depicted on the vertical axis while regional trade openness $\ln T$ is depicted on the horizontal axis (both are in the log form).

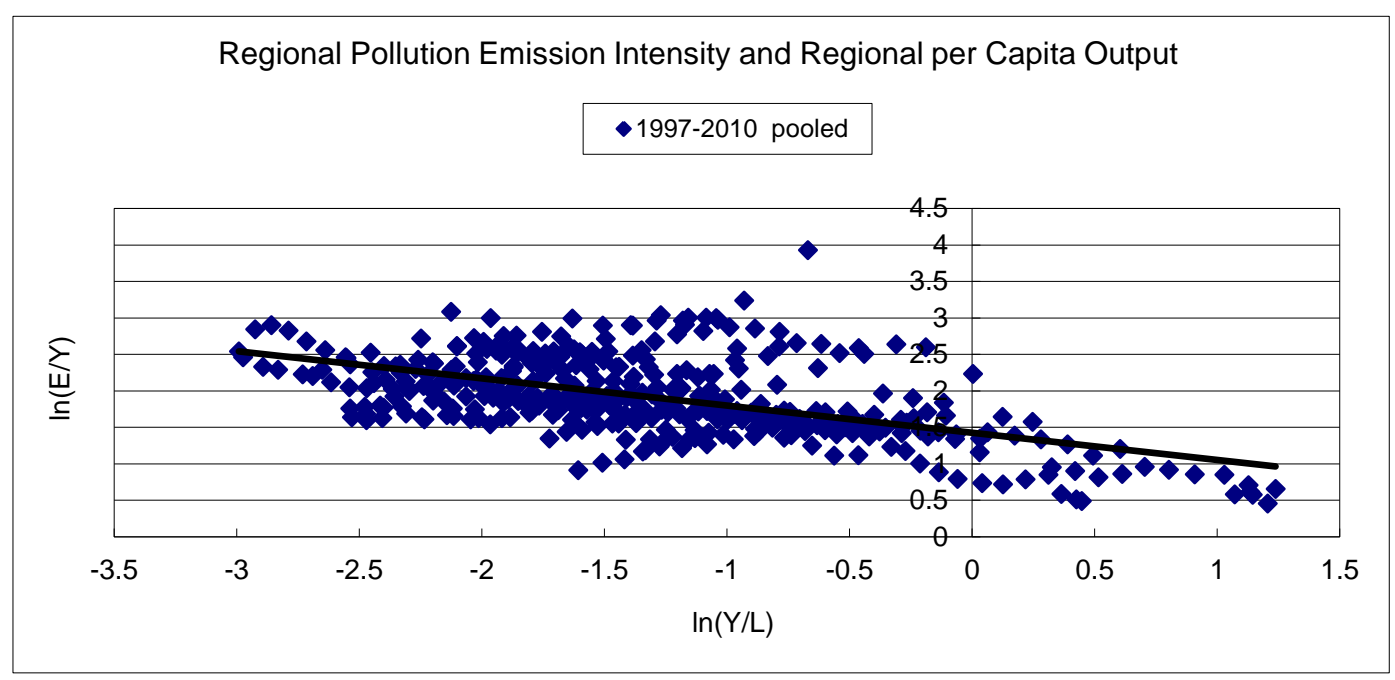

Figure 2. Regional Pollution Emission Intensity and Regional per Capita Output

Regional pollution emission intensity $\ln (\mathrm{E} / \mathrm{Y})$ is depicted on the vertical axis while regional per capita output $\ln (\mathrm{Y} / \mathrm{L})$ is depicted on the horizontal axis (both are in the log form).

Next, we show the relationship between regional pollution emission intensity and regional per capita output in Figure 2, also using pooled data of our entire sample period. The figure suggests a negative relationship between the two variables: 
the higher the provincial per capita output, the lower the provincial pollution emission intensity. Both Figures 1 and 2 find negative relationships. These findings are suggestive, but they are not very much compelling unless we can establish a ceteris paribus causal linkage, which we will attempt to do in our regression analysis to come. Besides the relationships depicted in Figures 1 and 2, we are also interested in seeing the linkage between regional pollution emission intensity and regional capital-output ratio. This is because we are interested in seeing the relationship between pollution emission intensity and investment, and according to the traditional Solow growth model the capital-output ratio is proportional to the investment rate along a balanced growth path. Therefore, in Figure 3, we depict the relationship between regional pollution emission intensity and regional capital-output ratio (pooled data). Unlike the two previous figures, Figure 3 does not seem to show any discernable pattern of the relationship between the two variables.

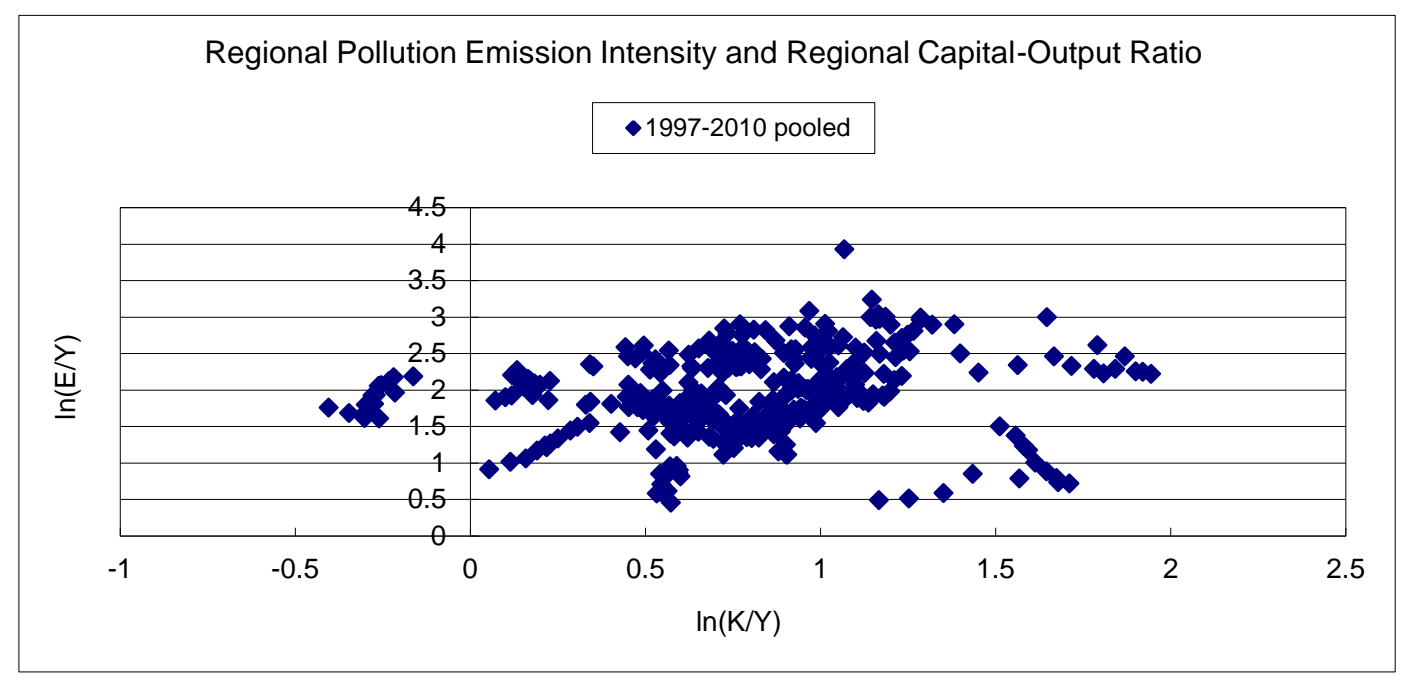

Figure 3. Regional Pollution Emission Intensity and Regional Capital-Output Ratio

Regional pollution emission intensity $\ln (\mathrm{E} / \mathrm{Y})$ is depicted on the vertical axis while regional capital-output ratio $\ln (\mathrm{K} / \mathrm{Y})$ is depicted on the horizontal axis (both are in the log form).

\section{Regression Results}

We use an annual data setup in our regression analysis: each period $t$ in Equations (8) and (13) pertains to a calendar year. There are 14 calendar years in our sample period of 1997-2010. Therefore, technically, we use 13 time (year) dummy variables, along with a common intercept, to take account of the time intercept $\delta_{t}$ in (8) and (13). Our regression results are summarized in Tables 1 and 2. The regressions in Table 1 are based on Equation (8) while those in Table 2 are based on Equation (13). Of the different regressions included, our preferred method is the fixed effects (FE) estimation as it controls for the time-constant province heterogeneity, but the other estimations (i.e. the first-differencing (FD), the random effects (RE), and the OLS estimations) are also included only for comparison purposes. ${ }^{3}$ To save space, in both tables, the estimated time intercepts (i.e. the estimated coefficients on the time dummy variables, along with the common intercept) are not reported.

The FE estimation in Table 1 produces significant estimated coefficients (at the usual 5\% level) on all the explanatory variables except $\left(\ln K_{i t}\right)^{2}{ }^{4}$ Particularly, the estimated coefficient on $\ln T_{i t}$ is significantly positive, which is about 0.12. This result suggests that once we have controlled for provincial output, population, and physical capital stock, provincial trade openness would have a positive effect on provincial pollution emission. As discussed earlier, when regional output, population, and physical capital stock are controlled for, regional trade openness may affect regional pollution emission by affecting either the level of aggregate total factor productivity or the regional industry mix (i.e. the relative shares of the output and inputs across different sectors).

The estimated coefficient on $\ln Y_{i t}$ is significantly positive, which is 2.093, while estimated coefficient on its squared term is significantly negative, which is -0.066 . Therefore, the partial effect of $\ln Y_{i t}$ on the dependent variable $\ln E_{i t}$ is estimated to be $2.093-0.132 \ln Y_{i t}$. This is equivalent to saying that the partial effect of $\ln Y_{i t}$ on the $\log$ of emission intensity, $\ln \left(E_{i t} / Y_{i t}\right)$, is $1.093-0.132 \ln Y_{i t}$. With regional population controlled for in the regression, this

\footnotetext{
${ }^{3}$ Both the FE and FD methods have the desirable feature of explicitly controlling for the unobserved province effects. However, the choice between FE and FD hinges on the assumptions about the idiosyncratic errors. Generally, the FE estimator is more efficient if the errors are serially uncorrelated while the FD estimator is more when the errors follow a random walk.

${ }^{4}$ Statistic significance mentioned in this study is always associated with the usual 5\% level unless otherwise stated.
} 
result supports the EKC hypothesis by showing that as (per capita) output grows larger, pollution emission (intensity) first increases and then falls. In our current sample, the maximal, minimal and average values of $\ln Y_{i t}$ are 9.000, 3.867 and 6.863, respectively. As $2.093-0.132 \ln Y_{i t}$ remains positive as long as $\ln Y_{i t}$ is smaller than 15.856 , we can see that in our sample, with all the other explanatory variables (including the unobserved province effects) being controlled for, provincial pollution emission increases all the way as provincial (per capita) output grows. However, as $1.093-0.132 \ln Y_{i t}$ stays positive while $\ln Y_{i t}$ is smaller than 8.280, we can see that provincial pollution emission intensity increases first and then falls as provincial (per capita) output grows.

Table 1. Regression Results Based on Equation (8)

\begin{tabular}{lcccc}
\hline \multicolumn{4}{l}{ Sample: 28 Chinese provinces 1997-2010 } & \multicolumn{3}{l}{ Obs: 392} \\
\hline Dependent variable: $\ln E_{i t}$ & FE & FD & RE & OLS \\
\hline Variables & $0.119^{* *}$ & -0.049 & -0.012 & $-0.165^{* *}$ \\
\hline $\ln T_{i t}$ & $(0.051)$ & $(0.060)$ & $(0.044)$ & $(0.033)$ \\
& $2.093^{* *}$ & $2.109^{*}$ & $1.208^{* *}$ & -0.472 \\
$\ln Y_{i t}$ & $(0.397)$ & $(1.120)$ & $(0.348)$ & $(0.410)$ \\
& $-0.066^{* *}$ & -0.045 & $-0.056^{* *}$ & $0.075^{* *}$ \\
$\left(\ln Y_{i t}\right)^{2}$ & $(0.028)$ & $(0.074)$ & $(0.026)$ & $(0.030)$ \\
$\ln L_{i t}$ & $-9.773^{* *}$ & -5.318 & $-5.130^{* *}$ & $-1.033^{*}$ \\
& $(1.990)$ & $(4.182)$ & $(1.213)$ & $(0.544)$ \\
$\left(\ln L_{i t}\right)^{2}$ & $0.640^{* *}$ & 0.362 & $0.336^{* *}$ & $0.081^{* *}$ \\
$\ln K_{i t}$ & $(0.135)$ & $(0.276)$ & $(0.078)$ & $(0.034)$ \\
& $0.843^{* *}$ & 1.186 & 0.514 & $1.240^{* *}$ \\
$\left(\ln K_{i t}\right)^{2}$ & $(0.331)$ & $(0.877)$ & $(0.323)$ & $(0.410)$ \\
\hline
\end{tabular}

Standard errors are in parentheses. * and ** denote significance at the $10 \%$ and $5 \%$ levels respectively. To save space, the estimated time intercepts (i.e. the estimated coefficients on the time dummy variables, along with the common intercept) are not reported in the table.

The estimated coefficient on $\ln L_{i t}$, which is -9.773 , and the one on its squared term, which is 0.640 , are both significant. The partial effect of $\ln L_{i t}$ on $\ln E_{i t}$ is therefore $-9.773+1.280 \ln L_{i t}$. According to our model earlier, as both $Y_{i t}$ and $K_{i t}$ are controlled for in the regression equation, a change in $L_{i t}$ must be associated with a change in either the level of total factor productivity or the level of resource input, or both. Our result shows that the partial effect is negative when $\ln L_{i t}$ stays low (lower than 7.635) and is positive when $\ln L_{i t}$ becomes high (higher than 7.635). In our current sample, the maximal, minimal and average values of $\ln L_{i t}$ are 9.238, 6.198 and 8.157, respectively. Therefore, provincial pollution emission (intensity) first falls and later rises as provincial population grows (with other explanatory variables being controlled for).

The estimated coefficient on $\ln K_{i t}$ is 0.843 , significantly positive at the $5 \%$ level, and that on $\left(\ln K_{i t}\right)^{2}$ is -0.042 , significantly negative at the $10 \%$ level. The partial effect of $\ln K_{i t}$ on $\ln E_{i t}$ is therefore $0.843-0.084 \ln K_{i t}$. Again, according to our model earlier, as both $Y_{i t}$ and $L_{i t}$ are controlled for in the regression specification, a change in $K_{i t}$ must be associated with a change in either the level of total factor productivity or the level of resource input, or both. Our result suggests that the partial effect is positive when $\ln K_{i t}$ is low (lower than 10.036), and negative when $\ln K_{i t}$ is high (higher than 10.036). In our current sample, the maximal, minimal and average values of $\ln K_{i t}$ are 10.036 , 4.795 and 7.717, respectively. Therefore, for our specific sample, provincial pollution emission (intensity) increases as provincial physical accumulates (with other explanatory variables being controlled for).

Table 2 includes an additional explanatory variable, the interaction term $\ln Y_{i t} \cdot \ln L_{i t}$, in the regression equation. According to Equation (13) and our discussion earlier, the inclusion of this variable slightly alters the interpretation of the openness variable (that is, it makes no difference whether it is $\ln T_{i t}$ or $\ln \ddot{T}_{i t}$ that appears as the dependent 
variable in (13)). In the FE regression in Table 2, the estimated coefficient on $\ln Y_{i t} \cdot \ln L_{i t}$ is insignificant. A quick comparison between the FE regressions in Tables 1 and 2 reveals that the inclusion of $\ln Y_{i t} \cdot \ln L_{i t}$ in the regression equation alters the estimated coefficients on all the other explanatory variable only very negligibly.

Table 2. Regression Results Based on Equation (13)

\begin{tabular}{lcccc}
\hline \multicolumn{2}{l}{ Sample: 28 Chinese provinces 1997-2010 } & \multicolumn{3}{c}{ Obs: 392} \\
\hline Dependent variable: $\ln E_{i t}$ & FE & FD & RE & OLS \\
\hline Variables & $0.119^{* *}$ & -0.051 & -0.012 & $-0.172^{* *}$ \\
\hline $\ln T_{i t}$ & $(0.051)$ & $(0.060)$ & $(0.044)$ & $(0.033)$ \\
& $2.153^{* *}$ & $1.916^{*}$ & $1.142^{* *}$ & $-0.746^{*}$ \\
$\ln Y_{i t}$ & $(0.432)$ & $(1.162)$ & $(0.398)$ & $(0.411)$ \\
& $-0.062^{* *}$ & -0.067 & $-0.060^{* *}$ & 0.012 \\
& $(0.030)$ & $(0.082)$ & $(0.028)$ & $(0.034)$ \\
$\left(\ln Y_{i t}\right)^{2}$ & $-10.211^{* *}$ & -5.026 & $-4.900^{* *}$ & -0.341 \\
$\ln L_{i t}$ & $(2.339)$ & $(4.210)$ & $(1.419)$ & $(0.569)$ \\
& $0.674^{* *}$ & 0.310 & $0.315^{* *}$ & -0.026 \\
& $(0.166)$ & $(0.288)$ & $(0.101)$ & $(0.045)$ \\
$\left(\ln L_{i t}\right)^{2}$ & $0.831^{* *}$ & 1.177 & 0.519 & $1.061^{* *}$ \\
$\ln K_{i t}$ & $(0.333)$ & $(0.878)$ & $(0.323)$ & $(0.407)$ \\
& $-0.041^{*}$ & -0.078 & -0.020 & $-0.065^{* *}$ \\
$\left(\ln K_{i t}\right)^{2}$ & $(0.024)$ & $(0.057)$ & $(0.023)$ & $(0.027)$ \\
$\ln Y_{i t} \cdot \ln L_{i t}$ & -0.018 & 0.071 & 0.015 & $0.143^{* *}$ \\
& $(0.051)$ & $(0.112)$ & $(0.042)$ & $(0.040)$ \\
\hline
\end{tabular}

Standard errors are in parentheses. * and $* *$ denote significance at the $10 \%$ and $5 \%$ levels respectively. To save space, the estimated time intercepts (i.e. the estimated coefficients on the time dummy variables, along with the common intercept) are not reported in the table.

\section{Extended Analysis}

The analysis above takes each Chinese province as an isolated region and does not consider potential strategic behavior among the provinces with respect to pollution emission. In this section, we incorporate strategic interaction among the provinces into our model. Regional pollution emission is related to the pollution abatement effort of the local government. However, local governments in China often have little incentive to favor greater effort in environmental protection and pollution abatement. Since the early 1990s, local governments have been experiencing budget deficits every year, and have relied heavily on transfers from the central government, which largely depends on value-added tax rebates. As value-added tax rebates are related to local output growth, local governments in China have strong incentives to increase local output (in order to increase revenue transfers), but have little incentive to protect the environment (Co, Kong and Lin, 2008). Therefore, the Chinese provinces may interact strategically in deciding on their levels of efforts in pollution abatement.

There are at least three reasons for possible strategic interaction among the provinces in the current case. The first reason is related to interregional competition for resources. For example, different provinces may interact strategically to attract and retain investment, foreign and domestic, which is often pollution-intensive, by racing down to the bottom of their environmental standards (Smarzynska and Wei, 2001; King, 2011). Secondly, there may exist interregional spillovers associated with the benefits from environmental protection and pollution abatement. A province may choose its level of effort in pollution abatement in response to pollution abatement spillovers it receives from other provinces (see, for example, Brueckner, 2003). Thirdly, interregional strategic interaction in pollution abatement behavior may also exist as a result of "information spillover" (see, for example, Besley and Case, 1995). For example, residents of a province may compare and evaluate their local government's performance in pollution abatement and environmental protection against other provinces, so that the local government may feel pressured to mimic the environmental policy of (say) a neighboring province. 
Table 3. Regression Results Based on Equation (14)

(The vector $\mathbf{X}_{i t}$ collects all the explanatory variables in Equation (8).)

\begin{tabular}{|c|c|c|c|c|}
\hline \multicolumn{3}{|c|}{ Sample: 28 Chinese provinces $1997-2010$} & \multicolumn{2}{|c|}{ Obs: 364} \\
\hline \multicolumn{5}{|c|}{ Dependent variable: $\ln E_{i t}$} \\
\hline Variables & $\mathrm{FE}$ & FD & $\mathrm{RE}$ & OLS \\
\hline \multirow{2}{*}{$\sum_{j \neq i} w_{i j} \ln E_{j, t-1}$} & 0.025 & 0.391 & -0.120 & 0.079 \\
\hline & $(0.305)$ & $(0.409)$ & $(0.160)$ & $(0.059)$ \\
\hline \multirow[t]{2}{*}{$\ln T_{i t}$} & $0.122 * *$ & -0.050 & -0.038 & $-0.143 * *$ \\
\hline & $(0.055)$ & $(0.064)$ & $(0.046)$ & $(0.038)$ \\
\hline \multirow[t]{3}{*}{$\ln Y_{i t}$} & $2.151 * *$ & $2.197 *$ & $1.444 * *$ & -0.592 \\
\hline & $(0.431)$ & $(1.168)$ & $(0.368)$ & $(0.441)$ \\
\hline & $-0.077 * *$ & -0.057 & $-0.069 * *$ & $0.079 * *$ \\
\hline$\left(\ln Y_{i t}\right)^{2}$ & $(0.030)$ & $(0.078)$ & $(0.028)$ & $(0.032)$ \\
\hline \multirow[t]{3}{*}{$\ln L_{i t}$} & $-8.328 * *$ & -4.849 & $-4.745^{* *}$ & $-0.993 *$ \\
\hline & $(2.314)$ & $(4.392)$ & $(1.268)$ & $(0.581)$ \\
\hline & $0.539 * *$ & 0.329 & $0.308^{* *}$ & $0.082 * *$ \\
\hline$\left(\ln L_{i t}\right)^{2}$ & $(0.158)$ & $(0.291)$ & $(0.082)$ & $(0.036)$ \\
\hline \multirow[t]{3}{*}{$\ln K_{i t}$} & $0.639 *$ & 1.042 & 0.363 & $1.283^{* *}$ \\
\hline & $(0.368)$ & $(0.928)$ & $(0.348)$ & $(0.447)$ \\
\hline & -0.030 & -0.070 & -0.012 & $-0.080 * *$ \\
\hline$\left(\ln K_{i t}\right)^{2}$ & $(0.026)$ & $(0.061)$ & $(0.024)$ & $(0.030)$ \\
\hline
\end{tabular}

Standard errors are in parentheses. * and ** denote significance at the $10 \%$ and $5 \%$ levels respectively. To save space, the estimated time intercepts (i.e. the estimated coefficients on the time dummy variables, along with the common intercept) are not reported in the table.

Taking this possible strategic interaction into consideration, we modify our earlier models into the following specification

$$
\ln E_{i t}=\rho \sum w_{i j} \ln E_{j, t-1}+\mathbf{X}_{i t} \boldsymbol{\beta}+\delta_{t}+c_{i}+\varepsilon_{i t}
$$

where $E_{j, t-1}$ refers to pollution emission in any ${ }^{j \neq j}$ ther province $j \quad(j \neq i)$ in the preceding period $t-1 .^{5} w_{i j}$ are nonnegative weights reflecting the relevant importance of other provinces $j$ in the process of strategic interaction, where the relevant importance is supposedly positively related to the geographical proximity between province $i$ and another province $j$. The vector $\mathbf{X}_{i t}$ then collects the explanatory variables in (8) and (13) (respectively). Different weighting schemes for $w_{i j}$ in (14) capture different spatial patterns of strategic interaction among the provinces. In this study, we adopt a "smooth distance decay" scheme in which we set $w_{i j}=1 / d_{i j}$ for $j \neq i$, where $d_{i j}$ is the distance between the capital cities of provinces $i$ and $j$. The unit of measurement for the distances is irrelevant because for each $i$ the weights will be normalized so that they add up exactly to unity.

We can now run regressions based on (14). The results are contained in Tables 3 and 4 . For the regressions in Table 3 the vector $\mathbf{X}_{i t}$ contains all the explanatory variables in (8) while for the regressions in Table 4 the vector $\mathbf{X}_{i t}$ contains all the explanatory variables in (13). In both tables, the estimates of the coefficient $\rho$ are all insignificant across all the regressions. Therefore, based on our results, we do not find evidence for the existence of strategic interaction among the Chinese provinces in terms of pollution abatement. Moreover, comparing Tables 3 and 4 with Tables 1 and 2, we can see that the inclusion of the additional explanatory variable in (14) alters the estimated values of the coefficients on all the other explanatory variables only very negligibly.

\footnotetext{
${ }^{5}$ We lag the levels of pollution emitted in the other provinces for one period in order to avoid the endogeneity problem induced by simultaneity. Besides this reason, it is also perfectly reasonable to assume that strategic reaction occurs with a time lag.
} 
Table 4. Regression Results Based on Equation (14)

(The vector $\mathbf{X}_{i t}$ collects all the explanatory variables in Equation (13).)

\begin{tabular}{|c|c|c|c|c|}
\hline \multicolumn{3}{|c|}{ Sample: 28 Chinese provinces $1997-2010$} & \multicolumn{2}{|c|}{ Obs: 364} \\
\hline \multicolumn{5}{|c|}{ Dependent variable: $\ln E_{i t}$} \\
\hline Variables & $\mathrm{FE}$ & FD & RE & OLS \\
\hline \multirow{2}{*}{$\sum_{j \neq i} w_{i j} \ln E_{j, t-1}$} & -0.018 & 0.409 & -0.120 & 0.020 \\
\hline & $(0.313)$ & $(0.411)$ & $(0.162)$ & $(0.061)$ \\
\hline \multirow[t]{2}{*}{$\ln T_{i t}$} & $0.122 * *$ & -0.051 & -0.038 & $-0.164 * *$ \\
\hline & $(0.055)$ & $(0.064)$ & $(0.046)$ & $(0.038)$ \\
\hline \multirow[t]{3}{*}{$\ln Y_{i t}$} & $2.261 * *$ & $2.012 *$ & $1.401 * *$ & $-0.815^{*}$ \\
\hline & $(0.466)$ & $(1.216)$ & $(0.420)$ & $(0.440)$ \\
\hline & $-0.068 * *$ & -0.077 & $-0.072 * *$ & 0.014 \\
\hline$\left(\ln Y_{i t}\right)^{2}$ & $(0.033)$ & $(0.086)$ & $(0.030)$ & $(0.037)$ \\
\hline \multirow[t]{3}{*}{$\ln L_{i t}$} & $-9.021 * *$ & -4.581 & $-4.607 * *$ & -0.373 \\
\hline & $(2.567)$ & $(4.424)$ & $(1.472)$ & $(0.603)$ \\
\hline & $0.595 * *$ & 0.282 & $0.295 * *$ & -0.026 \\
\hline$\left(\ln L_{i t}\right)^{2}$ & $(0.181)$ & $(0.303)$ & $(0.105)$ & $(0.045)$ \\
\hline \multirow[t]{3}{*}{$\ln K_{i t}$} & 0.610 & 1.042 & 0.365 & $1.096 * *$ \\
\hline & $(0.371)$ & $(0.929)$ & $(0.348)$ & $(0.444)$ \\
\hline & -0.028 & -0.071 & -0.012 & $-0.067 * *$ \\
\hline$\left(\ln K_{i t}\right)^{2}$ & $(0.026)$ & $(0.061)$ & $(0.024)$ & $(0.029)$ \\
\hline \multirow[t]{2}{*}{$\ln Y_{i t} \cdot \ln L_{i t}$} & -0.035 & 0.065 & 0.011 & $0.146^{* *}$ \\
\hline & $(0.056)$ & $(0.118)$ & $(0.045)$ & $(0.044)$ \\
\hline
\end{tabular}

Standard errors are in parentheses. * and ** denote significance at the $10 \%$ and $5 \%$ levels respectively. To save space, the estimated time intercepts (i.e. the estimated coefficients on the time dummy variables, along with the common intercept) are not reported in the table.

\section{Concluding Remarks}

In this study, we focus on uncovering the environmental implications of China's processes of opening up and economic development. We empirically investigate the effects of trade openness and the level of development on pollution emission across the Chinese provinces. By using panel data of 28 provinces in China over the period of 1997-2010, our regression analysis shows that when provincial output, population, physical capital stock as well as the unobserved province effects are properly controlled for, provincial openness to foreign trade tends to contribute to more serious provincial pollution emission. The effect of regional trade openness on regional pollution emission is supposedly realized through the impacts of the former on regional total factor productivity and the regional industry mix (the relative shares of the output and inputs across different sectors). In addition, our regression analysis also shows that along with continuous increases in regional output (and per capita output), regional pollution emission (and pollution emission intensity) would first rise and then fall, which conforms to what the EKC hypothesis predicts. By the same token, with provincial output, provincial physical capital stock as well as the unobserved province effects being properly controlled for, provincial pollution emission (and pollution emission intensity) would first fall and later rise as provincial population grows.

One important implication of our model and analysis in this study is that, when the effects of regional output, population, physical capital stock, as well as the unobserved region heterogeneity are properly taken account of, regional total factor productivity, which is associated with regional openness to foreign trade, is considered to play a crucial role in affecting regional pollution emission. Trade openness promotes aggregate total factor productivity. However, if a higher level of total factor productivity induces more pollution emission, this would indicate that such growth in total factor productivity is not totally "green" or environmentally sustainable. If this is the case, then increasing openness to foreign trade may lead to more serious pollution and a worsening environment, just as our regression analysis above has suggested. Given the findings of this study and their implications, the relationship between foreign trade, economic development and the environment should be brought under further scrutiny. 


\section{Acknowledgements}

The author thanks the anonymous Reviewer and the Editor of the Journal for their helpful comments. Of course, all remaining errors are the author's alone.

\section{References}

Abdulai, A., \& Ramcke, L. (2013). The Impact of Trade and Economic Growth on the Environment: Revisiting the Cross-Country Evidence. Journal of International Development, 25(2), 180-205. http://dx.doi.org/10.1002/jid.1789

Anselin, L. (1988), Spatial Econometrics. Dordrecht: Kluwer Academic Publishers.

Antweiler, W., Copeland, B. R., \& Taylor, M. S. (2001). Is Free Trade Good for the Environment? American Economic Review, 91(4), 877-908. http://dx.doi.org/10.1257/aer.91.4.877

Besley, T. J., \& Case, A. C. (1995). Incumbent Behavior: Vote Seeking, Tax Setting and Yardstick Competition. American Economic Review, 85, 25-45.

Brueckner, J. K. (2003). Strategic Interaction Among Governments: An Overview of Empirical Studies. International Regional Science Review, 26(2), 175-188. http://dx.doi.org/10.1177/0160017602250974

Co, C. Y., Kong, F., \& Lin, S. (2008). Pollution across Chinese Provinces. Development Economics Working Papers 22148, East Asian Bureau of Economic Research.

Cole, M. A. (2004). Trade, the Pollution Haven Hypothesis and the Environmental Kuznets Curve: Examining the Linkages. Ecological Economics, 48, 71-81. http://dx.doi.org/10.1016/j.ecolecon.2003.09.007

Economist, The. (2004). China's Environment: A Great Wall of Waste. August 19, 2004.

Gale, L. R., \& Mendez, J. A. (1998). The Empirical Relationship between Trade, Growth and the Environment. International Review of Economics and Finance, 7(1), 53-61. http://dx.doi.org/10.1016/S1059-0560(99)80016-1

Grossman, G. M., \& Krueger, A. B. (1993). Environmental Impacts of the North American Free Trade Agreement. In The U.S.-Mexico Free Trade Agreement, Garber, P. Massachusetts Institute of Technology, The MIT Press, Cambridge, MA., 13-56.

Grossman, G. M., \& Krueger, A. B. (1995). Economic Growth and the Environment. Quarterly Journal of Economics, 110(2), 353-377. http://dx.doi.org/10.3386/w4634

Jiang, Y. (2013). Total Factor Productivity, Pollution and "Green" Economic Growth in China. Journal of International Development, available online July 2013. http://dx.doi.org/10.1002/jid.2944

King, J. (2011). Foreign Direct Investment and Pollution Havens. Journal of Economics and Econometrics, 54(1), 39-47.

Low, P., Olarreaga M., \& Suarez, J. (1998). Does Globalization Cause a Higher Concentration of International Trade and Investment Flow? WTO Staff Working Paper ERAD-98-08 (August 1998), Economic Research and Analysis Division, World Trade Organization.

Mani, M., \& Wheeler, D. (1998). In Search of Pollution Havens? Dirty Industry in the World Economy, 1960-1995. Journal of Environment and Development, 7(3), 215-247.

Selden, T. M., \& Song, D. (1994). Environmental Quality and Development: Is There a Kuznets Curve for Air Pollution Emissions? Journal of Environmental Economics and management, 27, 147-162. http://dx.doi.org/10.1006/jeem.1994.1031

Smarzynska, B. K., \& Wei, S. J. (2001). Pollution Havens and Foreign Direct Investment: Dirty Secret or Popular Myth? NBER Working Papers 8465, National Bureau of Economic Research, Inc.

Tzouvelekas, E., Vouvaki, D., \& Xepapadeas, A. (2006). Total Factor Productivity Growth and the Environment: A Case for Green Growth Accounting. Working Papers 0617, University of Crete, Department of Economics.

Vincent, J. R. (1997). Testing for Environmental Kuznets Curves within a Developing Country. Environment and Development Economics, 2, 417-431. http://dx.doi.org/10.1017/S1355770X97000223

Zhang, J. (2008). Estimation of China's Provincial Capital Stock (1952-2004) with Applications. Journal of Chinese Economic and Business Studies, 6(2), 177-196. http://dx.doi.org/doi:10.1080/14765280802028302

Zhang, J. (2012). Delivering Environmentally Sustainable Economic Growth: The Case of China. Asia Society Report, September 2012.

\section{(c)) EY}

This work is licensed under a Creative Commons Attribution 3.0 License. 